\title{
Functional independence of elderly patients who fell: a follow-up study
}

\author{
Independência funcional de idosos que sofreram queda: estudo de seguimento \\ La independencia funcional de ancianos que sufrieron una caída: estudio de seguimiento
}

\section{Guilherme Guarino de Moura Sá' \\ ORCID: 0000-0003-3283-2656 \\ Ana Maria Ribeiro dos Santos ORCID: 0000-0002-5825-5335}

'Universidade Federal do Piauí. Teresina, Piauí, Brazil.

How to cite this article:

Sá GGM, Santos AMR. Functional independence of elderly patients who fell: a follow-up study. Rev Bras Enferm. 2019;72(6):1715-22. doi: http://dx.doi.org/10.1590/0034-7167-2018-0845

\section{Corresponding Author:}

Guilherme Guarino de Moura Sá E-mail: guilherme_mourasa@hotmail.com

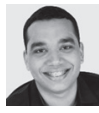

Submission: 08-10-2018 Approval: 03-04-2019

\section{ABSTRACT}

Objective: to evaluate, in emergency hospital service and at home, the functional independence of elderly people who fell. Method: longitudinal study with 151 elderly. Functional Independence Measure (FIM) was used. Statistical tests were performed with univariate and bivariate analysis. Results: mean of total FIM value in the hospital was 70.4; and at home $84.3(\mathrm{p}<0.001)$. Independence was lower in the motor domain, in "self-care", "mobility" and "locomotion" dimensions, in the two evaluations $(p<0.001)$. Dependence reduced from $97.3 \%$ elderly in the hospital to $82.8 \%$ at home $(p<0.001)$.There was a negative correlation between total FIM and age, number of medications, number of diseases and hospitalization time in both evaluations. Femoral and hip fractures were associated with lower total FIM values $(p<0.001)$. Conclusion: the elderly had less independence in the hospital compared to at home, with greater impairment in the motor domain and "selfcare", "mobility" and "locomotion" dimensions, in the two moments evaluated.

Descriptors: Aged; Longitudinal Studies; Accidental Falls; Activities of Daily Living; Geriatric Nursing.

\section{RESUMO}

Objetivo: avaliar, em serviço hospitalar de urgência e no domicílio, a independência funcional de idosos que sofreram queda. Método: estudo longitudinal com 151 idosos. Utilizou-se a Medida da Independência Funcional (MIF). Foram realizados testes estatísticos com análise univariada e bivariada. Resultados: a média da MIF total no hospital foi 70,4; e no domicílio 84,3 ( $p<0,001)$. A independência foi menor no domínio motor, nas dimensões "autocuidados", "mobilidade" e "locomoção", nas duas avaliações $(p<0,001)$. A dependência reduziu de $97,3 \%$ idosos, no hospital, para $82,8 \%$, no domicílio $(p<0,001)$. Houve correlação negativa entre MIF total e idade, número de medicamentos, número de doenças e tempo de internação em ambas as avaliações. As fraturas de fêmur e quadril associaram-se a menores valores da MIF total $(p<0,001)$. Conclusão: os idosos apresentaram menor independência no hospital em comparação ao domicílio, com maior comprometimento no domínio motor e dimensões "autocuidados", "mobilidade" e "locomoção", nos dois momentos avaliados.

Descritores: Idoso; Estudos Longitudinais; Acidentes por Quedas; Atividades Cotidianas; Enfermagem Geriátrica.

\section{RESUMEN}

Objetivo: evaluar, en el servicio hospitalario de urgencia y en el domicilio, la independencia funcional de ancianos que sufrieron una caída. Método: estudio longitudinal con 151 ancianos. Se utilizó la Medida de la Independencia Funcional (MIF). Se realizaron pruebas estadísticas con el análisis univariado y bivariado. Resultados: el promedio de la MIF total en el hospital fue 70,4; en el domicilio fue $84,3(p<0,001)$. La independencia fue menor en el dominio motor, en las dimensiones "autocuidados", "movilidad" y "locomoción", en las dos evaluaciones $(p<0,001)$. La dependencia disminuyó del 97,3\% de los ancianos, en el hospital, al $82,8 \%$, en el domicilio $(p<0,001)$. Se observó una correlación negativa entre la MIF total y la edad, número de medicamentos, número de enfermedades y tiempo de internación en ambas las evaluaciones. Las fracturas de fémur y cadera se asociaron a menores valores de la MIF total $(p<0,001)$. Conclusión: los ancianos presentaron menor independencia en el hospital en comparación con el domicilio, con más compromiso en el dominio motor y las dimensiones "autocuidados", "movilidad" $y$ "locomoción" en los dos momentos evaluados.

Descriptores: Anciano; Estudios Longitudinales; Accidentes por Caídas; Actividades Cotidianas; Enfermería Geriátrica. 


\section{INTRODUCTION}

Population aging is a worldwide phenomenon that outlines demands on health services. Among these demands, accidents due to falls in the elderly are highlighted by the high prevalence of emergency room care and the physical, emotional and functional consequences for this population ${ }^{(1)}$.

In this study, fall was defined by the World Health Organization as "an unintentional displacement of the body to a level lower than the initial position, incapable of correction in a timely manner, as determined by multifactorial conditions that compromise stability"(2).

In the world, falls represent one of the main causes of care for the elderly in emergency services and accounts for 10 to $15 \%$ of geriatric care. This event still accounts for $40 \%$ of lesion-related deaths. In addition, approximately $28 \%$ to $35 \%$ of people over 65 years old fall every year, with the frequency increasing with the age of the elderly ${ }^{(2)}$.

A recent national study has found that $41 \%$ of hospitalizations due to external causes in public hospitals were due to falls; and of these the hospitalization coefficient revealed that most of the victims were people over 60 years of age ${ }^{(3)}$. A population-based survey also found that in Brazil the prevalence of falls in the elderly with a need to seek health services was $7.8 \%{ }^{(4)}$.

The main consequences of these accidents are bone and muscle injuries, which compromise the functional independence of the elderly and result in limitation of activities of daily living ${ }^{(1,5-6)}$. Thus, functional independence is an important marker of the health of the elderly, and it is essential that it is evaluated by the health team to follow up losses, rehabilitation evaluation and planning of care lines, regardless of type or degree of assistance.

Functional independence is defined as the ability to live independently in the community with some or no help from others to perform activities of daily living, whereas dependence is the inability to perform tasks satisfactorily without the help of another person or equipment that allows him to $\operatorname{adapt}^{(7)}$. Functional independence evaluation contributes to the implementation and operationalization of health care policies for the elderly. In this sense, preventive, care and rehabilitation actions in health should aim to improve functionality and its losses.

In this perspective, a six-year follow-up study with elderly patients who fell in the United States identified that the participants remained with an important functional impairment in this period ${ }^{(8)}$. In Spain, a prospective cohort study found that during the six months of follow-up of the elderly hospitalized in the emergency department after falling independence rates decreased significantly ${ }^{(9)}$.

Therefore, because it is an event of multifactorial cause of high therapeutic complexity, with serious consequences and of difficult prevention, fall requires scientific investigations with different approaches. In addition, impairments in the independence of the elderly may play an important role in the multicausal interaction of falls and may represent an independent risk factor for mortality ${ }^{(10)}$.

Despite the existence of current studies on the subject, population surveys that evaluate functional independence in the longitudinal perspective are still discrete, especially in the Brazilian reality ${ }^{(11)}$. Considering the magnitude of falls effects, it is necessary to know the interference of these in functional independence of the elderly in different moments after the accident.

\section{OBJECTIVE}

To evaluate functional independence of elderly patients who fell in hospital emergency service and at home.

\section{METHOD}

\section{Ethical aspects}

This study was conducted according to the norms of Resolution $466 / 2012$ of the National Health Council/Ministry of Health, and approved by the Research Ethics Committee of the Universidade Federal do Piauí.

\section{Design, place of study and period}

This is a longitudinal study, carried out in a hospital of emergency reference in trauma care, of a capital of Northeast Brazil, through a structured interview with hospitalized elderly people who fell in the period between April and September 2016.

\section{Population or sample; inclusion and exclusion criteria}

For the sample calculation, it was considered the $95 \%$ confidence coefficient, error of $5 \%$, and the proportion of $13.4 \%$, corresponding to the prevalence of elderly patients who fell and were hospitalized in the hospital from January to December of 2013 (which dealt with the most current computerized data recorded in the Serviço de Arquivo Médico e Estatística (freely translated as Medical Archive and Statistics Service) of the institution during the research period). Thus, the sample size of 174 elderly recruited by consecutive sampling was established.

Included in the study were elderly individuals aged 60 or over who were hospitalized, where the cause of hospitalization was the fall, who had a fixed or mobile telephone line for later contact and returned home after discharge. The hospitalized elderly undergoing surgical procedure were excluded before functional independence evaluation in the hospital because they considered that this procedure interfered in the evaluation results.

Following the 30-day follow-up of the 174 interviewees at the emergency hospital, 13 were lost because they were transferred to another hospital after the interview; five due to rehospitalization before the 30-day post-discharge period; one due to death; and four because the researcher did not obtain the subsequent telephone contact after five attempts at contact at different times. Thus, 151 elderly patients completed the study of functional independence in hospital in emergency and 30 days after discharge at home.

\section{Study protocols}

The following instruments were used for data collection: 1) Mini-Mental State Examination (MMSE), used to evaluate cognitive function and to minimize possible errors in the understanding of the instruments, adjusted for years of schooling ${ }^{(12)}$; 2) Script for the characterization of sociodemographic and clinical profile, prepared by the members of the Grupo de Estudos em Envelhecimento 
e Causas Externas de Morbimortalidade (GEECEM - Studies Group on Aging and External Morbimortality Causes) of the Universidade Federal do Piauí; 3) Functional Independence Measure (FIM) ${ }^{(13-14)}$.

In order to fill out the script for characterization of the elderly, "hospitalization time" and "fracture types" variables were extracted from the records in the medical record and in the Authorization for Hospitalization (AlH - Autorização de Internação Hospitalar).

For fracture types categorization, according to the International Classification of Diseases 10th revision - ICD-10: Upper limb fractures (S422 - Humerus fracture; S424 - Fracture of lower end of humerus; S520 - Unspecified fracture of upper end of right ulna; S525 - Fracture of lower end of radius; S526 - Fracture of lower end of ulna; S623 - Fracture of other and unspecified metacarpal bone; S626 - Fracture of other and unspecified finger(s)); Fracture of femur or hip (S324 -Fracture of acetabulum; S720 - Fracture of neck or femur; S721 - Pertrochanteric fracture; S722 - Subtrochanteric fracture of femur; S723 - Fracture of shaft or femur; S724 - Fracture of lower end of femur; S730 - Subluxation and dislocation of hip); Fracture of lower limb (S820 - Fracture of lateral patella, S821 - Fracture of upper end of tibia, S823 - Fracture of lower end of tibia, S826 - Fracture of lateral malleolus).

FIM, translated and validated in Brazil, aims to quantitatively assess the burden of care required by a person to perform a series of motor and cognitive tasks of daily living. It has been used by several rehabilitation centers in several countries and evaluates 18 functional tasks: 13 motor and five cognitive ${ }^{(13-14)}$.

In motor FIM, values range from 13 to 91 , while cognitive FIM values range from 5 to 35 . Thus, in total FIM, values range from 18 to 126 , which can be divided into four subscores, according to total score obtained: a) 18 points: complete dependence (total assistance); b) 19-60 points: modified dependence 1 (assistance of up to $50 \%$ of the task); c) 61-103 points: modified dependence 2 (assistance of up to $25 \%$ of the task); d) 104-126 points: complete/modified independence. Therefore, the lower the score the higher the level of dependence and the worse the functional performance of the elderly, and the higher the score the greater the functional independence ${ }^{(13-14)}$.

Data collection was performed in two stages. The first stage was developed in the sectors of prompt care and orthopedic clinic, since these units are responsible for the reception and care of patients with trauma. At this stage, the elderly's cognitive status was assessed (in cases where they did not present cognitive conditions, the companion, aged $\geq 18$ years old and residing with him, was asked to answer questions related to the elderly) and were collected sociodemographic and clinical data. In addition, the first application of FIM regarding functional independence of the interview moment was performed on the first day of hospitalization.

The second stage occurred 30 days after discharge from the elderly by phone contact to evaluate functional independence, with the elderly person at home.

\section{Analysis of results and statistics}

Data were processed by the software Statistical Package for the Social Sciences (SPSS), version 21.0. The Kolmogorov-Smirnov Test was used to evaluate variables normality, in order to subsidize the choice of other tests to be used. Categorical variables were described by means of absolute and relative frequency, and the continuous variables were analyzed by means of central tendency measures, such as mean and standard deviation, or median and interquartile range, according to the normality test.

For comparison between values of domains and dimensions of FIM in the hospital and at home, the Paired Sample T-Test and the Wilcoxon Signed-Rank Test were applied. The Test of Marginal Homogeneity was used to analyze the evolution of functional independence of the elderly. Total FIM association with fractures was verified by the T-Test for independent samples use. In order to analyze the correlation between total FIM and independent quantitative variables, the Pearson correlation tests (for "age" variable) and Spearman (for "number of medications","number of diseases" and "hospitalization time" variables). Correlation graphs were constructed with the aid of the statistical program R. The significance level adopted for the statistical tests was $5 \%(p<0.05)$.

\section{RESULTS}

Of the 151 elderly participants, $81.5 \%(n=123)$ were female. The prevalent age group was the younger age group (60 to 79 years), corresponding to $64.9 \%(n=98)$, with a range ranging from 60 to 103 years, with an average of 75.1 years and the standard deviation of 9.7. Regarding schooling, $73.5 \%(n=111)$ were not literate and $87.8 \%(n=129)$ were retired.

Regarding clinical aspects of the elderly, $48.3 \%(n=73)$ selfreferenced two to three diseases, with a median of 2.0 (1.0-3.0). Cardiovascular system diseases ( $n=103 / 68.2 \%)$, osteoarticular diseases ( $n=87 / 57.6 \%$ ), endocrine, metabolic and nutritional disorders ( $n=47 / 31.1 \%)$ and vision $(n=47 / 31.1 \%)$. As to the number of medications used, $41.1 \%(n=73)$ of the elderly used two to three medications, the median being 2.0 (2.0-4.0).

Lesions suffered by the elderly were femoral and/or hip fractures ( $n=74 / 48.7 \%)$, upper limb fractures $(n=66 / 43.42 \%)$ and lower limb fractures $(n=12 / 7.9 \%)$. Hospitalization time ranged from two to 21 days, with a median of 7.0 (6.0-8.0).

Regarding functional independence evaluation, Table 1 presents values and variations of dimensions and domains of FIM in the two evaluations. In the hospital, the results showed values far from the maximum FIM score and its dimensions, which represent functional dependence at that time, with greater impairment in the motor domain, in "self-care", "mobility" and "locomotion" dimensions. When comparing values in the hospital and at home, it was observed a rise in the mean of the total FIM, pointing to the improvement of independence.

It was observed, therefore, in Table 1, that functional independence of the elderly was lower, with a statistically significant difference during hospitalization ( $p<0.05$ ).

In the hospital, $2.7 \%$ of the elderly were independent; and at home, $17.2 \%$ were in this condition. Thus, in the hospital, $97.3 \%$ of the elderly had some dependence and, after 30 days of discharge, at home, this percentage reduced to $82.8 \%$ (Table 2).

Table 2 shows that after 30 days of follow-up there was an increase in the number of independent elderly $(p<0.001)$.

Table 3 shows the association of the total FIM values with the types of fracture suffered by the elderly. 
Table 1 -Functional Independence Measure, its domains and respective dimensions in the two moments of evaluation,Teresina, Piauí, Brazil, 2016 ( $N=151$ )

\begin{tabular}{|c|c|c|c|c|c|c|c|c|}
\hline \multirow{2}{*}{$\begin{array}{l}\text { Domains and } \\
\text { dimensions }\end{array}$} & \multirow[b]{2}{*}{ PV } & \multicolumn{2}{|c|}{ Hospital } & \multicolumn{4}{|c|}{ At home } & \multirow{2}{*}{$p$ value } \\
\hline & & OV & $\square$ (SD) & Md(IQI) & ov & $\square$ (SD) & Md(IQI) & \\
\hline Motor FIM & $13-91$ & $13-87$ & 43.1(16.4) & $40(29-57)$ & $13-91$ & $55.6(17.3)$ & $59(42-68)$ & $<0.001^{*}$ \\
\hline Self-care & $6-42$ & $6-42$ & $18.7(8.3)$ & $17(12-26)$ & $6-42$ & $25.1(7.6)$ & $27(20-30)$ & $<0.001^{*}$ \\
\hline Sphincter control & $2-14$ & $2-14$ & $12.1(3.2)$ & $14(12-14)$ & $2-14$ & $12.9(2.6)$ & 14(13-14) & $<0.001^{*}$ \\
\hline Mobility & $3-21$ & $3-21$ & $7.3(4.9)$ & $6(3-12)$ & $3-21$ & $11.1(5.7)$ & $12(6-15)$ & $<0.001^{*}$ \\
\hline Locomotion & $2-14$ & $2-14$ & $4.9(3.7)$ & $2(2-8)$ & $2-14$ & $6.5(4.4)$ & $5(2-10)$ & $<0.001^{*}$ \\
\hline Cognitive FIM & $5-35$ & $5-35$ & $27.3(7.3)$ & $30(26-31)$ & $5-35$ & $28.7(6.4)$ & $31(27-32)$ & $<0.001^{*}$ \\
\hline Communication & $2-14$ & $2-14$ & $12.4(3.3)$ & $14(12-14)$ & $2-14$ & $12.8(2.8)$ & $14(13-14)$ & $0.002^{*}$ \\
\hline Social cognition & $3-21$ & $3-21$ & $15.0(4.4)$ & $16(14-18)$ & $3-21$ & $15.9(4.0)$ & $17(14-18)$ & $<0.001^{*}$ \\
\hline Total FIM & $18-126$ & $18-122$ & $70.4(21.2)$ & $69(57-87)$ & $18-126$ & $84.3(22.0)$ & $89(70-100)$ & $<0.001^{* *}$ \\
\hline
\end{tabular}

Note: $P V=$ Possible Variation; $O V=$ Observed Variation; $\square=$ Mean; SD = Standard Deviation; Md = Median; IQI = Interquartile Interval; *Wilcoxon Signed-Rank Test; *Paired Sample T-Test; FIM = Functional Independence Measure.

Table 2 - Levels of functional independence of the elderly in the hospital and at home - Teresina, Piauí, Brazil, 2016 (N=151)

\begin{tabular}{|c|c|c|c|c|c|}
\hline \multirow[b]{2}{*}{ Category } & \multicolumn{2}{|c|}{ Hospital } & \multicolumn{2}{|c|}{ At home } & \multirow[b]{2}{*}{$p$ value } \\
\hline & $n(\%)$ & $\mathrm{Cl}_{95 \%}$ & $n(\%)$ & $\mathrm{Cl}_{95 \%}$ & \\
\hline Complete dependence & $2(1.3)$ & $0.0-3.3$ & $2(1.3)$ & $0.0-3.3$ & \multirow{5}{*}{$<0.001$} \\
\hline Modified dependence 1 & $48(31.8)$ & $24.5-39.1$ & $20(13.3)$ & 7.9-19.2 & \\
\hline Modified dependence 2 & $97(64.2)$ & $57.0-72.2$ & $103(68.2)$ & $60.9-74.8$ & \\
\hline Complete/modified independence & $4(2.7)$ & $0.7-5.3$ & $26(17.2)$ & $11.3-23.2$ & \\
\hline Total & $151(100.0)$ & & $151(100.0)$ & & \\
\hline
\end{tabular}

Note: *Test of Marginal Homogeneity.

Table 3 -Total Functional Independence Measure association with fractures of the elderly after the fall, Teresina, Piauí, Brazil, 2016 (N=151)

\begin{tabular}{|c|c|c|c|c|}
\hline \multirow[b]{2}{*}{ Fraturas } & \multicolumn{2}{|c|}{ Hospital } & \multicolumn{2}{|c|}{ At home } \\
\hline & Mean (SD) & $p$ value ${ }^{*}$ & Mean (SD) & $p$ value ${ }^{*}$ \\
\hline \multicolumn{5}{|c|}{ Upper limb fracture } \\
\hline No (85) & $60.6(17.6)$ & $<0.001$ & $75.0(19.4)$ & $<0.001$ \\
\hline Yes (66) & $83.1(18.8)$ & & $96.4(19.1)$ & \\
\hline \multicolumn{5}{|c|}{ Femur and/or hip fracture } \\
\hline No (77) & $83.2(17.9)$ & $<0.001$ & $96.5(17.1)$ & $<0.001$ \\
\hline Yes (74) & $57.1(15.5)$ & & $71.6(19.1)$ & \\
\hline \multicolumn{5}{|c|}{ Lower limb fracture } \\
\hline No (139) & $69.8(21.4)$ & 0.253 & $83.9(22.5)$ & 0.452 \\
\hline Yes (12) & $77.2(18.8)$ & & $88.9(14.6)$ & \\
\hline
\end{tabular}

Note: *T-Test for independent samples.

Regarding total FIM association with types of fractures, Table 3 shows that, both in the hospital and at home, the elderly with fracture of upper limbs presented a statistically significant higher FIM mean when compared to those who did not have this type of lesion $(<0.001)$. On the other hand, in the two evaluations, the elderly with some type of fracture of the femur and/or hip were less independent when compared to those who did not present these lesions $(<0.001)$.

Correlations results between total FIM in the hospital and the age and clinical characteristics (number of medications, hospitalization time and number of diseases) are shown in Figure 1.

Figure 1 shows that, in the hospital, a negative and statistically significant correlation was found between FIM and age $(r$ $-0.545 / p<0.001)$, number of medications $(r-0.175 / p=0.032)$, number of diseases $(r-0.190 / p=0.019)$ and hospitalization time $(r-0.336 / p<0.001)$.

Figure 2 shows the correlations between total FIM scores at home and age and clinical characteristics (number of medications, hospitalization time and number of diseases).
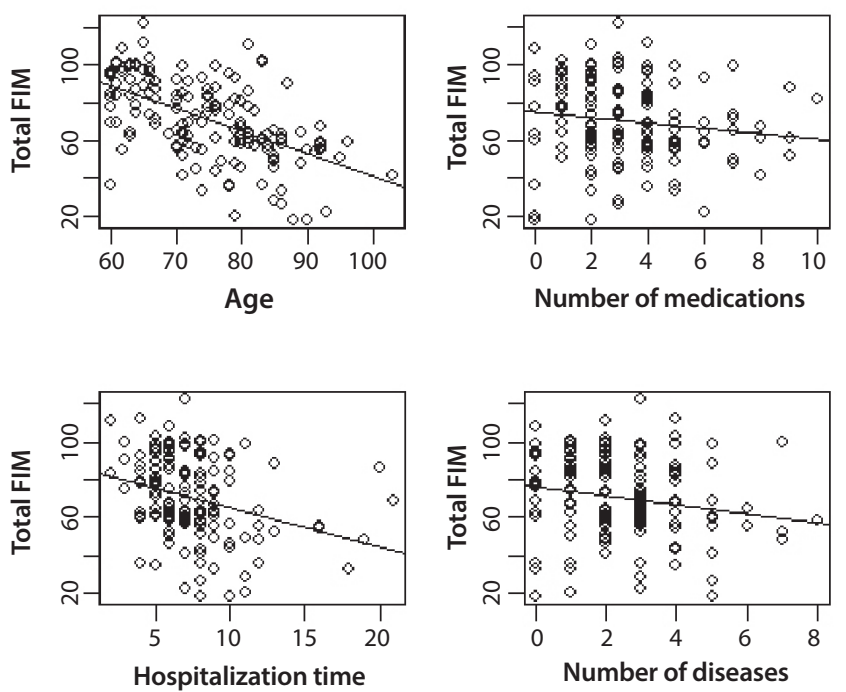

Figure 1 - Correlation of total Functional Independence Measure scores in the Hospital with age, number of medications, hospitalization time and number of diseases, Teresina, Piauí, Brazil, $2016(\mathrm{~N}=151)$ 

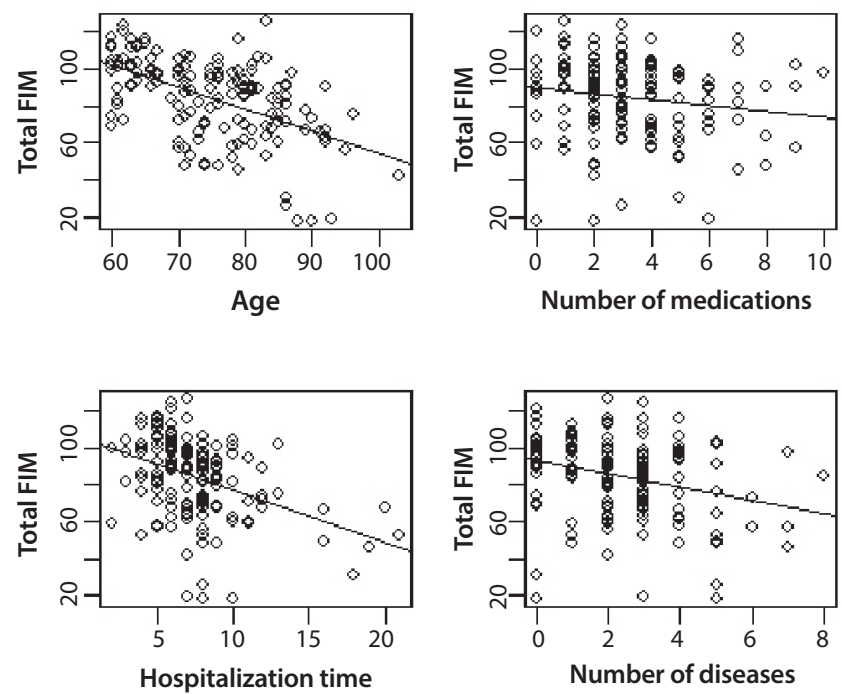

Figure 2 - Correlation of total Functional Independence Measure scores at home with age, number of medications, hospitalization time and number of diseases, Teresina, Piauí, Brazil, $2016(\mathrm{~N}=151)$

Figure 2 shows that, at home, a negative and statistically significant correlation was also found between FIM and age $(r$ $-0.529 / p<0.001)$, number of medications $(r-0,195 / p=0.017)$, number of diseases $r-0.256 / p=0.002$ ) and hospitalization time $(r-0.399 / p<0.001)$.

Correlation coefficients in the hospital and at home indicated, therefore, that with the increase of the age, there is a decline of functional independence. Likewise, as the number of medications increases, the number of diseases and the hospitalization time, functional independence of the elderly declines.

\section{DISCUSSION}

Functional independence evaluation through FIM made it possible to measure independence and quantify the demand for help from third parties for the daily activities of the elderly, in the hospital and at home. FIM has been used in international research mainly for rehabilitation evaluation in follow-up studies. Nationally, its use has been limited to cross-sectional studies ${ }^{(11)}$. In this sense, Gerontology researchers should be encouraged to use this instrument that is well accepted in the scientific community, in researches with different methodological designs.

The findings of this study revealed that the elderly who fell and were hospitalized in an emergency hospital presented lower independence in the hospital compared to the measure of functional independence after 30 days of discharge at home. At hospitalization, the greatest changes were observed in "self-care", "mobility" and "locomotion" dimensions. Similar results were also found in research evaluating functional independence of elderly people who fell in Canada, Spain, and Taiwan ${ }^{(15-16)}$.

Mobility and locomotion impairment of the elderly with fracture, consequently, affects the activities of self-care, which may justify functional limitations found. In addition, in the hospitalization, the client moves away from the familiar and social conviviality and is relocated to an unknown and turbulent environment. This is an important reality to consider, since independence in performing daily life activities involves issues of an emotional, physical and social nature ${ }^{(17)}$. It points to a greater monitoring, on the part of the nurse, of the activities that the elderly person can accomplish at that moment. In addition, it is important to emphasize the importance of teaching the companion to assist in carrying out the tasks, with respect to the autonomy of the elderly.

It is important to emphasize the importance of health professionals, especially the nurse, when evaluating the tasks that the elderly person can perform at home, considering the previous hospitalizations, as they may interfere directly with functional capacity, independence and autonomy ${ }^{(18)}$. Hospitalization is lived more complex by the elderly, when compared to the younger, because it is more easily associated with death, dependenc and disease ${ }^{(19)}$; for this reason, causes stress, anxiety and anxiety, especially in emergency services, where the elderly present serious and unusual situations in their daily life.

In this study, fractures suffered by the elderly after the fall were the cause of hospitalizations in the emergency hospital. Those who had upper limb fractures had higher total FIM values in comparison to those who did not suffer from this type of fracture. These results are different from those found in a prospective cohort study in Spain that evaluated functional changes in the daily life of the elderly who suffered a fractured wrist and identified that there was a decline in functional status during the six months of follow-up of the study ${ }^{(9)}$.

On the other hand, this result is justified by observing that the elderly who did not suffer fractures of upper limbs had at least one hip or femur fracture, which presented lower FIM values. This finding is consistent with the literature, confirming hip and femur fractures as the main lesions resulting from falls and causing dependence ${ }^{(4,20)}$.

Lesions in the elderly produces more serious repercussions than among younger people ${ }^{(21)}$. In this sense, fractures directly influence the ability of the elderly to perform activities of daily living, since they cause pain and limit movement. When considering that these are common and serious consequences of falls, it is important that nurses carry out educational interventions with relatives and caregivers of the elderly to prevent falls; and to show the consequences of these as a way of encouraging the necessary modifications in the environment. In addition, the recognition by the elderly of vulnerability to falls that produce fractures is a relevant aspect to be considered for the implementation of prevention strategies ${ }^{(22)}$.

In this study, it was found that the older the age of the elderly, the inversely proportional was the result of the independence evaluation. Similarly, a study conducted in the United States found that the older the elderly the greater the functional dependence rates among those who suffered some lesion caused by fall(23).

Physical exhaustion and fragility, most clearly manifested in people over 80 years of age, as a consequence of a complex causal network of the decline in functional independence, may explain these results ${ }^{(24)}$. Independence takes different patterns over time, and the fall seems to interrupt, abruptly and negatively this process, which can anticipate health problems, arising from the injuries caused and the disabling process. Thus, it is indispensable that the nurse knows the profile of the elderly population identifies risk factors and acts in the prevention of disabilities. 
The nurse's role is fundamental to assist the elderly in the recognition and development of their potential for self-care, and to encourage support and involvement of caregivers. The nurse should also seek to know safe techniques and assistive technologies that promote or guide caregivers regarding the mobility and locomotion of injured elderly patients who consider the inherent limitations of the lesion.

Therefore, there is a need to implement preventive measures to avoid accidents due to falls not only to people in the age group that corresponds to old age, but also to young adults who should be encouraged to live as a fundamental foundation of a healthy life expectancy.

Most of the elderly participants in the present study used two to three medications. Results also showed a negative correlation between FIM values and the number of medications used by the elderly. Polypharmacy is divided into small, when there is use of two or three medications, moderate, with consumption of four to five and large, over five medications, and may occur as a consequence of multiple chronic diseases ${ }^{(25)}$. In Spain, a study identified that polypharmacy affected the independence of the elderly ${ }^{(9)}$. Besides being a risk for falls, this practice is associated with medication interactions, changes in balance, functional impairment and fragility ${ }^{(26)}$.

Medications handling by the elderly with low level of schooling can favor the error and, for this reason, requires supervision and intensification of systematic care processes. Thus, it is inherent to the nurse's role to guide the correct medication taking, in order to minimize functional consequences in the elderly. The importance of non-pharmacological therapeutic interventions, guided by nurses during community education actions, is also added, considering the uniqueness of each patient.

Results showed a negative correlation between FIM values and the number of self-reported diseases. This result converges with the change in the Brazilian epidemiological profile, which includes as a characteristic the increase in Chronic Noncommunicable Diseases ${ }^{(27)}$. It is important that the elderly affected by multiple pathologies be followed-up by a multiprofessional team that recognizes the consequences of such problems. Follow-up by the nurse during the treatment is necessary, in order to evaluate the dependencies caused in the elderly, as a result of those diseases that may predispose to falls.

It was also observed that the longer the hospitalization time of the elderly patients who fell the lower values of functional independence in the hospital and at home. The inactivity of the bedridden patient in this environment can mainly affect the musculoskeletal system. Thus, functional limitations can impair transfers, postures and movement, as well as hamper basic activities, alter gait patterns, and increase the risk of pressure injuries ${ }^{(28)}$.

Therefore, it is imperative, therefore, the direct action of the nurse in the planning of care for the elderly who fell and in care behaviors that minimize hospitalization time, aiming at the prevention of immobility, which seems to favor the dependence. Comprehensive care should consider the multidimensionality of the elderly person, since the perception of hospitalization per se is a potential limiting motor function.

In this way, functional independence evaluation is timely for the monitoring and prevention of functional losses and limitations arising from senescence or senility and its consequences; especially in the follow-up of elderly people who fell. It is incumbent on nurses to adopt strategies that corroborate the prevention of fall accidents and formal instruments that assess independence and measure what the elderly person is able to do, with a view to promoting active aging. However, progress in studies that develop care protocols for the follow-up of elderly dependents due to.

\section{Study limitations}

As limitations of this study, it is pointed out that it is performed only in a public hospital, not possibly portraying other realities, such as those of private hospitals. It is also recognized that the 30-day follow-up does not allow generalization of all the implications of functional independence decline and may differ from the results of longer follow-up studies. However, it reveals important aspects for immediate care interventions in the rehabilitation of functional independence of the elderly.

\section{Contributions to the fields of Nursing, Health or Public Policy}

The follow-up of the elderly who fell allowed knowing to know the demands of care in different moments of rehabilitation. It should be emphasized, therefore, that realizing functional changes is linked to the implementation of care based on technical evaluations and not only empirical. This study broadens the discussions about an important consequence of falls in the elderly: the impairment of functional independence that outlines limits on the social participation of the elderly. It also allows nurses to perceive functional alterations of the elderly after the fall, in the first moments of rehabilitation. In addition, adequate behavior should be rethought that may reduce the magnitude of this consequence of accidents due to falls, whether in hospital care or Primary Health Care.

Nursing must take on the demands of the human aging and, thus, develop strategies to promote active and healthy aging. Therefore, it is necessary to invest in the Permanent Education of health professionals, in particular nurses, regarding the knowledge about independence evaluation, prevention of functional losses and care for dependent elderly people. In addition, knowledge about the risk factors for falls in the elderly and interventions to prevent these accidents.

\section{CONCLUSION}

Functional independence evaluation in the hospital and at home, after 30 days of discharge, through the application of FIM, in elderly patients hospitalized in an emergency reference hospital, after a fall, allowed to conclude that the elderly had less independence in the hospital, in compared to the measure of independence at home. Motor domain and "self-care", "mobility" and "locomotion" dimensions presented lower FIM values in the two moments after the accident, indicating impairment of functional independence. The elderly who suffered femur and/or hip fractures presented less independence. In both evaluations, a negative and statistically significant correlation was found between total FIM and age, number of medications, number of diseases and hospitalization time. 
The creation and development of multisectoral actions based on the determinants for the promotion of an active aging, aimed at the promotion of a healthy aging, with autonomy and independence preservation, is necessary, especially considering the accelerated population aging and the fall as one of the events that most affect this population. Therefore, it is necessary to carry out other studies with a longitudinal design that evaluate functional independence of the elderly in different periods of follow-up in other rehabilitation settings and compare the influence of different interventions on functional independence of the elderly who fell.

\section{REFERENCES}

1. Harmsen AMK, Reijnders UJL, Giannakopoulos GF. Death as a consequence of a hip fracture after a fall; to be further investigated? Arch Trauma Res. 2016;5(4):e33705. doi: 10.5812/atr.33705

2. World Health Organization (WHO). WHO Global Report on Falls Prevention in Older Age [Internet]. Geneva: WHO; 2010 [cited 2015 Apr 14]. Available from: http://www.who.int/ageing/publications/Falls_prevention7March.pdf

3. Mascarenhas MDMM, Barros MBA. Evolution of public health system hospital admissions due to external causes - Brazil, 20022011. Epidemiol Serv Saúde. 2015;24(1):19-29. doi: 10.5123/S1679-49742015000100003

4. Pimentel WRT, Pagotto V, Stopa SR, Hoffmann MCCL, Malta DC, Menezes RL. Quedas com necessidade de procura de serviços de saúde entre idosos: uma análise da Pesquisa Nacional de Saúde, 2013. Cad Saúde Pública. 2018;34(8):e00211417. doi: 10.1590/0102-311x00211417

5. Patel BD, Limbasiya R. Incidence and consequence of fall in indian older adults: a survey. International Journal of Physical Education Sports Management and Yogic Sciences [Internet]. 2016 [cited 2017 Nov 10];6(1):13-21. Available from: http://www.indianjournals.com/ijor.aspx?ta rget=ijor:ijpesmys\&volume $=6 \&$ issue $=1$ \&article $=003 \&$ type $=$ pdf

6. Alves AHC, Patrício ACFA, Fernandes KA, Duarte MCS, Santos JS, Oliveira MS. Occurrence of falls among elderly institutionalized: prevalence, causes and consequences. J Res Fundam Care Online. 2016;8(2):4376-86. doi: 10.9789/2175-5361.2016.v8i2.4376-4386

7. World Health Organization (WHO). Active aging: a policy framework [Internet]. Geneva: WHO; 2002 [cited 2015 Apr 18]. Available from: https://extranet.who.int/agefriendlyworld/wp-content/uploads/2014/06/WHO-Active-Ageing-Framework.pdf

8. Mamikonian-Zarpas A, Laganá L. The relationship between older adult's risk for a future fall and difficulty performing activities of daily living. J Aging Gerontol. 2015;3(1):8-16. doi: 10.12974/2309-6128.2015.03.01.2

9. Vergara I, Vrotsou K, Orive M, Garcia-Gutierrez S, Gonzalez N, Las Hayas C, et al. Wrist fractures and their impact in daily living functionality on elderly people: a prospective cohort study. BMC Geriatr. 2016;16:11. doi: 10.1186/s12877-015-0176-z

10. Borim FSA, Francisco PMSB, Neri AL. Sociodemographic and health factors associated with mortality in community-dwelling elderly. Rev Saúde Pública. 2017;51:42. doi: 10.1590/s1518-8787.2017051006708

11. Ribeiro DKMN, Lenardt MH, Lourenço TM, Betiolli SE, Seima MD, Guimarães CA. The use of the functional independence measure in elderly. Rev Gaúcha Enferm. 2017;38(4):e66496. doi: 10.1590/1983-1447.2017.04.66496

12. Bertolucci PHF, Brucki SMD, Campacci SR, Juliano Y. O Mini-Exame do Estado Mental em uma população geral impacto da escolaridade. Arq Neuro-Psiquiatr. 1994;52(1):1-7. doi: 10.1590/S0004-282X1994000100001

13. Riberto $M$, Miyazaki MH, Jorge Filho D, Sakamoto H, Battistella LR. Reprodutibilidade da versão brasileira da Medida de Independência Funcional. Acta Fisiátr. 2001;8(1):45-52. doi: 10.5935/0104-7795.20010002

14. Riberto M, Miyazaki MH, Jucá SSH, Sakamoto H, Pinto PPN, Battistella LR. Validation of the Brazilian version of Functional Independence Measure. Acta Fisiátr. 2004;11(2):72-6. doi: 10.5935/0104-7795.20040003

15. Best JR, Davis JC, Liu-Ambrose T. Longitudinal analysis of physical performance, functional status, physical activity, and mood in relation to executive function in older adults who fall. J Am Geriatr Soc. 2015;63(6):1112-20. doi: 10.1111/jgs.13444

16. Yu HW, Chen DR, Chiang TL, Tu YK, Chen YM. Disability trajectories and associated disablement process factors among older adults in Taiwan. Arch Gerontol Geriatr. 2015;60(2):272-80. doi: 10.1016/j.archger.2014.12.005

17. Wang J, Boehm L, Mion LC. Intrinsic capacity in older hospitalized adults: implications for nursing practice. Geriatr Nurs. 2017;38(4):359-61 . doi: 10.1016/j.gerinurse.2017.06.008

18. Ribeiro EG, Matozinhos FP, Guimarães GL, Couto AM, Azevedo RS, Mendoza IYQ. Self-perceived health and clinical-functional vulnerability of the elderly in Belo Horizonte/Minas Gerais. Rev Bras Enferm [Internet]. 2018;71(suppl 2):860-7. [Thematic Issue: Health of the Elderly]. doi: 10.1590/0034-7167-2017-0135

19. Sanson G, Perrone A, Fasci A, D’Agostino F. Prevalence, Defining Characteristics, and Related Factors of the Nursing Diagnosis of Anxiety in Hospitalized Medical-Surgical Patients. J Nurs Scholarsh. 2018;50(2):181-90. doi: 10.1111/jnu.12370

20. Rodríguez-Molinero AR, Narvaiza L, Gálvez-Barrón C, De La Cruz JJ, Ruíz J, Gonzalo N, et al. Caídas en la población anciana española: incidencia, consecuencias y factores de riesgo. Rev Esp Geriatr Gerontol. 2015;50(6):274-80. doi: 10.1016/j.regg.2015.05.005

21. Luzardo AR, Paula Jr NF, Medeiros M, Wolkers PCB, Santos SMA. Repercussions of hospitalization due to fall of the elderly: health care and prevention. Rev Bras Enferm [Internet]. 2018;71(suppl 2):763-9. [Thematic Issue: Health of the Elderly] doi: 10.1590/0034-7167-2017-0069

22. Carvalho CJA, Bocchi SCM. The elderly recognizing themselves as vulnerable to falls in the concreteness of the femoral fracture. Rev Bras 
Enferm [Internet]. 2017;70(2):279-86. doi: 10.1590/0034-7167-2016-0392

23. Cigolle CT, Ha J, Min LC, Lee PG, Gure TR, Alexander NB, et al. The epidemiologic data on falls, 1998-2010: more older Americans report falling. JAMA Intern Med. 2015;175(3):443-5. doi: 10.1001/jamainternmed.2014.7533

24. Ribeiro DKMN, Lenardt MH, Michel T, Setoguchi LS, Grden CRB, Oliveira ES. Contributory factors for the functional independence of oldest old. Rev Esc Enferm USP. 2015;49(1):87-93. doi: 10.1590/S0080-623420150000100012

25. Paula Jr JD, Barros Jr JC, Gonçalves JC, Oliveira AV, Reis MRG. Prática de polifarmácia por idosos cadastrados em unidade de atenção primária. Investigação. 2013;13(2):15-8. doi: 10.26843/investigacao.v13i2

26. Bonaga B, Sánchez-Jurado PM, Martínez-Reig M, Ariza G, Rodríguez-Mañas L, Gnjidic D, et al. Frailty, polypharmacy, and health outcomes in older adults: the frailty and dependence in Albacete study. J Am Med Dir Assoc. 2018;19(1):46-52. doi: 10.1016/j.jamda.2017.07.008

27. Melo-Silva AM, Mambrini JVM, Souza Jr PRB, Andrade FB, Lima-Costa MF. Hospitalizations among older adults: results from ELSI-Brazil. Rev Saúde Pública. 2018;52(Suppl 2):3s. doi: 10.11606/s1518-8787.2018052000639

28. Everink IHJ, van Haastregt JCM, van Hoof SJM, Schols JMGA, Kempen GIJM. Factors influencing home discharge after inpatient rehabilitation of older patients: a systematic review. BMC Geriatr. 2016;16:5. doi: 10.1186/s12877-016-0187-4 